emissions through the incineration process. It is important to note that items which are not contaminated such as paper towels after we wash our hands and even instrument pouches should end up in the general waste. On the whole the most frequent item found in the clinical waste is disinfectant wipes which are used for the infection control process in between patients. ${ }^{4}$

While working as a dental nurse a few years ago, I came across a practice in which E-Cloth Professional microfibre cloths were used instead of disinfectant wipes. They were used just with water, no chemicals required, and autoclaved once used on ten patients. This practice was essentially generating minimal amounts of waste each day, which led me to think about how effective this chemical-free cloth is and whether we can use it safely.

Whilst studying BSc Biomedical Science I proposed and undertook primary research testing the microfibre cloth in question; I used a real life dental setting environment to gain more reliable results. From statistical analysis the E-Cloth Professional showed significant reduction of bacterial colonies; colony counts were significantly lower than the counts for the chemical-containing disinfectant wipes also used in the study. ${ }^{5}$ However, a larger sample size and longer study would provide more confidence.

\section{How can you help?}

DCPs are excellent and experienced educators; their communication skills and knowledge on how to motivate others comes naturally with the job role. It would be a shame not to use these skills in promoting sustainable living to patients and in turn help with current local and global issues.

Things to consider in our everyday life:

- Use reusable water bottles

- Compost food waste and donate food to banks

- Conserve water - turn off the tap when brushing teeth

- Use a bike/public transport as much as possible

- Recycle your waste appropriately, making sure it is not contaminated with food, so wash it out

- Swap to eco-friendly products but do your own research

- Speak up and educate people around you!
What to consider when choosing sustainable products in dentistry There have been some great new dental products on the market this past year or so, but we have to do our own research before recommending these to patients.

- First of all, we should educate ourselves on sustainable products and try them out, making sure they will fit patients' needs and will not compromise their oral health

- Secondly, not all products that are marketed as 'sustainable' are actually environmentally friendly; we need to ask ourselves where was this product made and where is it coming from? Has it been transported into the UK via air, road? Try and use products that have been manufactured locally as the biggest threat to the environment is carbon dioxide emissions generated by transportations of goods. ${ }^{6}$ for Sustainable Healthcare. Carbon modelling within dentistry: Towards a sustainable future. July 2018. Available at: https://assets.publishing.service.gov. uk/government/uploads/system/uploads/ attachment_data/file/724777/Carbon_ modelling_within_dentistry.pdf_(accessed 24 May 2021).

3. NHS England. Greener NHS campaign to tackle climate 'health emergency'. 25 January 2020. Available at: https://www. england.nhs.uk/2020/01/greener-nhscampaign-to-tackle-climate-healthemergency/ (accessed 4 June 2021).

4. Richardson J, Grose J, Manzi S et al. What's in a bin: A case study of dental clinical waste composition and potential greenhouse gas emission savings. Br Dent $J$ 2016; 220: 61-66.

5. Jaslikowska D, Davda L. An investigation into the decontamination of dental

\section{'It is important to note that items which} are not contaminated such as paper

\section{towels after we wash our houds and}

\section{even instrument pouches should}

\section{end up in the general waste.'}

- Lastly, we need to know how these products can be disposed of; some, although marketed as biodegradable, are made of nylon which makes it impossible to recycle. The nylon bristles have to be taken off with pliers before placing it into the compost waste - is this a safe option for patients? Make sure to read manufacturers' instructions as they vary for some brands, and do not be afraid to contact the company for more information.

\section{References}

1. World Health Organization. Climate change and health. 1 February 2018. Available at: https://www.who.int/newsroom/fact-sheets/detail/climate-changeand-health (accessed 24 May 2021)

2. Public Health England and Centre work surfaces: a comparison of biocide wipes with an environmentally friendly alternative. Annual Clin J Dent Health 2021; 10: 28-32. Available at: https:// bsdht01.worldsecuresystems.com/ publications/ACJ/ACJ\%20Low-res.pdf (accessed 4 June 2021).

6. Department for Business, Energy, \& Industrial Strategy. 2019 UK greenhouse gas emissions, provisional figures. 26 March 2020. Available at: https://assets. publishing.service.gov.uk/government/ uploads/system/uploads/attachment_data/ file/875485/2019_UK_greenhouse_gas_ emissions_provisional_figures_statistical_ release.pdf (accessed 4 June 2021).

https://doi.org/10.1038/s41407-021-0650-8 